\section{Going to the Dogs: Free-Ranging Domestic Dogs Threaten an Endangered Wild Canid through Competitive Interactions}

\author{
Laura Rebecca Perry ${ }^{1 *}$, Jorgelina Marino ${ }^{1,2,3}$ and Claudio Sillero-Zubiri ${ }^{1,2,3}$ \\ ${ }^{1}$ Wildlife Conservation Research Unit, Department of Zoology, The Recanati-Kaplan Centre, Tubney House, Tubney, OX13 5QL, UK \\ ${ }^{2}$ Ethiopian Wolf Conservation Programme, Dinsho, Ethiopia \\ ${ }^{3}$ IUCN SSC Canid Specialist Group, Oxford, UK
}

"Corresponding author: Laura Rebecca Perry, Wildlife Conservation Research Unit, Department of Zoology, The Recanati-Kaplan Centre, Tubney House, Tubney, OX13 5QL, UK, Tel: +447702304851; E-mail: laura.perry@zoo.ox.ac.uk

Received date: February 02, 2018; Accepted date: February 23, 2018; Published date: February 27, 2018

Copyright: $@ 2018$ Perry LR, et al. This is an open-access article distributed under the terms of the creative commons attribution license, which permits unrestricted use, distribution, and reproduction in any medium, provided the original author and source are credited.

\begin{abstract}
Domestic dogs threaten wildlife globally, especially other canids. The spread of infectious disease from dogs threatens Ethiopian wolves, via interference and exploitation competition. Despite increasing threats to wildlife from dogs, competition between dogs and wild carnivores is relatively unstudied. This study seeks to understand the behavior and habitat use of free-ranging dogs in the Bale Mountains National Park, Ethiopia, and their interactions with other park users, through focal animal follows totaling > 150 hours. Dogs used the same areas as wolves, foraged throughout wolf habitat, and aggressively interacted with wolves in their territories. Wolves were actively displaced from foraging grounds by dogs, with dogs chasing wolves both while foraging alone or when moving with livestock. Direct competition for small mammals was not sustained by these results. Female dogs may make less extensive use of wolf range; they covered significantly less distance and interacted less aggressively with wolves. Domestic dogs are increasingly present in protected areas around the globe, and this study documents their negative impact on wild carnivores-both through direct interaction and use of habitat - highlighting the implications of dog presence for wildlife conservation.
\end{abstract}

Keywords: Bale mountains National Park; Canis lupus familiaris; Canis simensis, Ethiopia; Ethiopian wolf; Human-wildlife conflict; Inter-specific competition

\section{Introduction}

From the High Arctic to the Arabian desert [1] there are an estimated 700 million domestic dogs (Canis lupus familiaris) across the globe [2]. Given burgeoning global dog populations and increasing evidence of conflict between dogs and wildlife $[3,4]$ there is a growing need to understand their behavior. Across the diverse environments dogs inhabit, considerable variation in the behavior and ecology of free-ranging dogs is to be expected; for example, some studies suggest that free-ranging dogs may be able to subsist on entirely wild food sources [1], but the majority have at least partial reliance on humans and human derived materials including food refuse, crops, livestock, human faeces, and other food given directly to the dogs [5]. There is considerable evidence that free-ranging dogs prey on wildlife, from small rodents to large-bodied ungulates, both opportunistically and indiscriminately [5]. Indeed, the ability to exploit both human derived and wild food sources makes dogs an even greater threat to wildlife, with dog populations reaching unnaturally high densities-in urban environments densities of up to $1,509 \mathrm{dogs} / \mathrm{km}^{2}$ have been reported [6].

Dogs have a considerable potential to actively threaten wildlife $[7,8]$, not only through direct predation; competitive interactions are also likely to be important. Intra-guild competition has been widely shown to impact community structure in carnivores $[9,10]$ an effect that is particularly evident in canids [5]. Wolves displace coyotes (Canis latrans) from carcasses [11] red foxes (Vulpes vulpes) prevent arctic foxes (Vulpes lagopus) from using habitat [12] and coyotes are the main source of mortality for kit foxes (Vulpes macrotis) [13]. These interaction dynamics have also been documented between freeroaming dogs and other wild canids [14] found that Indian fox distribution and habitat use was determined by presence of freeranging dogs, probably due to interference competition [15]. Exploitative competition has also been documented in African carnivores [16]. Since exploitation arises from joint use of the same limiting resources, it becomes more likely with increasing similarity between species. Catholic diets, medium body size and wide habitat suitability make free-ranging dogs a prime candidate for documenting exploitation competition between relatives.

One such relative is the Ethiopian wolf (Canis simensis). Endemic to Ethiopia's diminishing Afroalpine habitat and IUCN Red Listed as Endangered [17], Ethiopian wolves are both the most endangered carnivore in Africa and the rarest canid in the world [17]. The continued loss of their specialist habitat and diseases are the most imminent dangers to populations $[18,19]$. Specifically, Ethiopian wolf populations are threatened by rabies and canine distemper virus (CDV), for which domestic dogs are the principal vectors and the reservoir species, allowing these diseases to persist in the system, thereby representing pathogen-mediated apparent competitors to the wolves [20,21].

While disease transmission and hybridization [22] are documented threats, the potential for interference and exploitation competition between dogs and wolves has not been adequately characterized. Despite its importance to wolf conservation, a paucity of information surrounds uses of shared habitat in the Bale Mountains by these human-owned, but free-ranging, dogs [23] demonstrated that rodents, 
the main food of Ethiopian wolves, form only a small proportion of the diet of free-ranging dogs, but interference competition is not adequately understood by dietary analysis alone. More importantly, the number of dogs in the Bale Mountains National Park continues to increase [24], under which conditions the importance of competition between wolves and dogs may continue to increase. Specifically, it is hypothesized that exploitative competition occurs through dogs limiting wolf access to critical habitat, and that interference competition occurs when wolves and dogs inhabit the same area, with larger, male animals behaving more aggressively than smaller females. Activity patterns, particularly foraging behaviors, were studied to explore these hypotheses and investigate the nature of the interspecific relationship between dogs and Ethiopian wolves.

\section{Methods}

\section{Study area and free-ranging dogs}

The Bale Mountains National Park (BMNP, Figure 1), in Ethiopia's south-eastern highlands, provides a home to half of the world's remaining Ethiopian wolves $[25,26]$. Characterized by extremely cold nights and mild days, the dry season typically runs from October to March; between April and September there is a warmer wet season, with rainfall concentrated in two peaks in April-May and SeptemberOctober [27]. Protecting roughly 2,140 $\mathrm{km}^{2}$ [28] BMNP represents a range of habitats. Despite its protected status, the human population inside BMNP is both sizeable and growing, with an estimated 35,000 users in 2009. Three thousand of these households are in core wolf territory, in the Afroalpine zone (>3,000 $\mathrm{m}$ a.s.l.) [24,29].

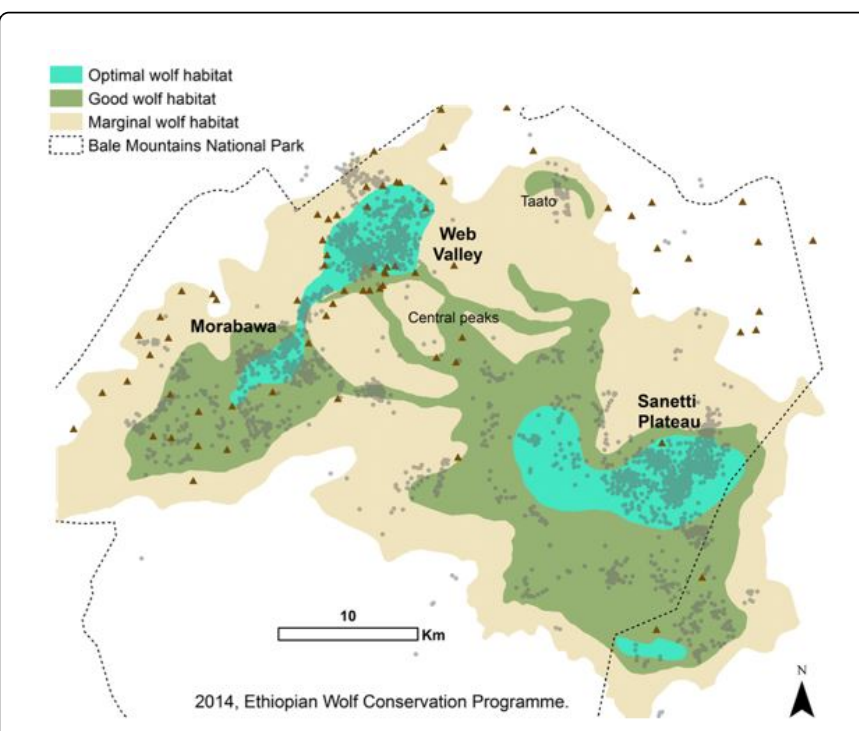

Figure 1: Bale Mountains National Park. Colors indicate quality of habitat for Ethiopian wolves. The Web Valley study area is in the North-West of the Afroalpine range in BMNP. Grey points are Ethiopian wolf locations 2013-2014. Brown triangles are human settlements.

This study was carried out in the Web Valley of BMNP $\left(39^{\circ} 40^{\prime} \mathrm{N}\right.$, $7^{\circ} 0^{\prime} \mathrm{E}$ ) from June to September 2015 . Situated at $\sim 3,500 \mathrm{~m}$ elevation, the valley comprises roughly $70 \mathrm{~km}^{2}$ of prime wolf habitat, harboring the highest density of wolves in the world [29]. Whilst the central valley is largely flat, it is walled by rocky cliffs to the west and south. Skirting this area are 9 main villages, as well as numerous smaller homesteads of 1-2 households. These settlements largely hug the valley walls, although development is slowly encroaching on the central wolf habitat. Domestic dogs are kept by all households - with up to 6 dogs per household- for livestock guarding purposes: spotted hyaena (Crocuta crocuta) and leopard (Panthera leo Pocock, 1927) are present within the region [30] and Ethiopian wolves occasionally predate lambs [29]. Households have defined perimeters, but dogs are free to roam both in villages and beyond.

Following the definition of $[5,31,32]$ dogs in BMNP are characterized as rural 'free-ranging, i.e. "dogs that are owned but not confined to a proscribed outdoor area". These animals are not actively fed by humans but may be dependent on human-derived materials such as barley husks and human faeces for survival [23]. Although dogs are free to roam, most do not: animals largely remain around the homestead of their owners, with only c. $3 \%$ of the population roaming widely in the valley [23].

\section{Field methods}

Dogs were observed using focal sampling techniques [33] with focal individual(s) followed on horseback. Whilst focal animal follows are not suitable for all species or habitats, they were in this case: BMNP is an open environment, and dogs are neither elusive nor fast-moving so follow methodology was deemed appropriate. Focal animals were selected opportunistically based on encounters in the park, or by following animals out of homesteads. Although individual animals were not identified, homestead specificity and individual markings allowed approximate identification of individuals, and ensured each dog was not sampled repeatedly. Those animals remaining in homesteads or villages were excluded. Most focal animals were followed until they returned home $(n=102)$; in a few cases the focus of a follow opportunistically shifted to another animal. Occasionally focal animals were lost (for example when a focal animal moved into impassable terrain, $n=15)$, or abandoned prematurely $(n=2)$.

Dogs were highly tolerant of human presence, allowing detailed observations to be made from 5-500 m (using Bushnell $10 \times 42$ Power view binoculars $w$ here necessary). Although animals were vocal and aggressive in villages, in the wider park they ignored the presence of researchers. Based on the identification of coat patterns and homesteads, repeat sampling of individual animals was avoided as far as possible, but animals were not highly distinctive, so some animals may have been sampled repeatedly. All animals were sexed and placed into age classes, separating adults and sub-adults. To achieve more balanced sampling, female animals were preferentially followed.

After a preliminary period to establish the hours over which the dogs were active, follows were largely carried out between 07:00 and 16:00 hrs. Two observers were present for the duration of all follows one either a member of the Ethiopian Wolf Conservation Programme (EWCP) monitoring staff or an official BMNP scout, the other the primary researcher. Data were recorded at between 3 and 5-minute intervals, with additional records of unusual or noteworthy behavior, including attempts at predation and interactions with wolves. Each record included GPS position, habitat type (using EWCP guidelines) and focal animal identity. Presence of additional non-focal animals was documented, separated into sex and age classes where possible. Behavior was categorized into 27 categories [33]. Associations of focal 
Citation: Perry LR, Marino J, Sillero-Zubiri C (2018) Going to the Dogs: Free-Ranging Domestic Dogs Threaten an Endangered Wild Canid through Competitive Interactions. J Biodivers Endanger Species 6: 211. doi:10.4172/2332-2543.1000211

Page 3 of 7

animals with other park users were recorded based on the presence of people and/or livestock within $50 \mathrm{~m}$ of the focal animal.

\section{Data analysis}

This study gathered 1,862 records over 132 observational follows, of which 1,629 records were of focal animals. Of those, 25 were female, comprising $\sim 19 \%$ of the dataset, and all-bar-one focal animals were adult. The follow was the unit of analysis for summarizing the prevalence of different activity classes, and for understanding individual behavior. Where possible $(\mathrm{n}=94)$, the home village of each focal animal was identified by following animals to or from their village. It was not possible to sample villages evenly (with 2, 15, 3, 6, 6, 18, and 44 focal animals from Alando, Doda, Gata, Mulamo, Tarbo, Wola and Sodota, respectively).

Of the 27 classes into which behavior was originally categorized, for analysis this was collapsed into 5 main classes: foraging, eating, travelling, interactions and stationary behavior. Foraging behavior was separated from eating behavior to understand differences between foraging and success of foraging; these two classes were subsequently merged where more appropriate. Travelling is defined as movement through habitat without any foraging activity. All social behavior, both intraspecific and interspecific, fell under the umbrella of 'interaction' behavior. Whenever focal animals were not moving - i.e. standing, sitting or lying - this was classed as 'stationary' behavior. Where suitable, all records of dogs outside of villages were pooled $(n=1,843)$.

Analyses were carried out using R v.3.1.2, employing ggplot2, plotrix, vcd, lubridate, Brewer and Hmisc packages, all of which are open source. QGIS v.2.12 was used to map spatial data. The inbuilt Convex Hull Geoprocessing tool mapped the ranging behavior of dogs from each village, creating $100 \%$ convex polygons for dogs from each village. Additional data was provided by the EWCP.

\section{Results}

\section{Behavior and movement patterns of free-ranging dogs}

Excluding follows $<10$ minutes in duration, mean follow length of was 63 minutes $( \pm$ SE 6.95 ). Female follow lengths (mean $36.86 \pm$ SE 6.77) were significantly shorter than male follows (mean $70.08 \pm \mathrm{SE}$ 8.34; $\mathrm{t}$-test, $\mathrm{p}=0.0031$ ). The range of follow length was also greater for males, with the longest male follow $>350$ minutes, compared to 131 minutes for females. Dogs left their homestead a long while after sunrise, with less than $2 \%$ of follows leaving before 08:00 hrs. Dog presence in wolf range was concentrated around midday, with the median record between 11:00-12:00 hrs. Over 90\% of dog activity away from homesteads occurred between 08:00-15:00 hrs, and 50\% were between 10:00-13:00 hrs (Figure 2).

Having entered the valley floor, dogs ranged freely through different habitat types, spending most of their time in alpine grassland (43.6\%), swamp (17.5\%) and Alchemilla (17.2\%). Behavior was significantly dependent on habitat type $(\mathrm{X} 2, \mathrm{df}=28, \mathrm{p}$-value $<2.2 \mathrm{e}-16)$. Stationary behavior was more likely in grassland and alpine grassland (mosaic test, Pearson residuals 2.0-3.1), and foraging behavior significantly more likely in swamp habitat (mosaic test, Pearson residuals $>4.1$ for foraging in swamp).

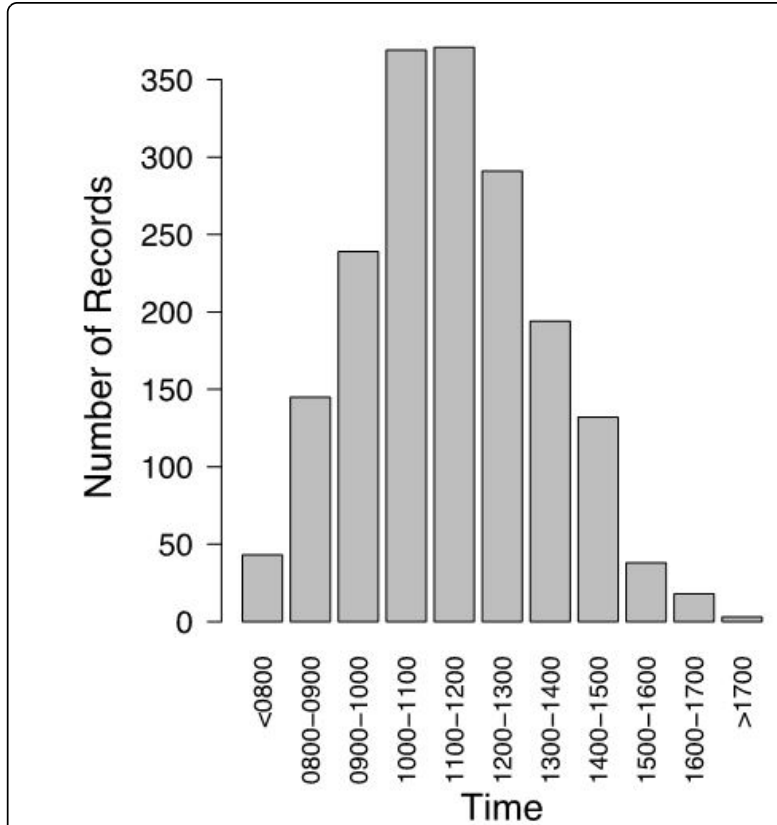

Figure 2: Time of Dog Presence in Wolf Habitat. Records of dogs in the BMNP $(n=1,843)$. Modal and median records are both between 11:00 and 12:00 hrs. 90\% of records occurred between 08:00-15:00 hrs, and 50\% of records between 10:00-13:00 hrs.

No other behavior/habitat relations were individually significant. Although foraging emerged as the principal activity on the majority of follows (45.8\% of records), the proportion of time spent on each behavior was highly variable, both by individual animal and time period (Figure 3).

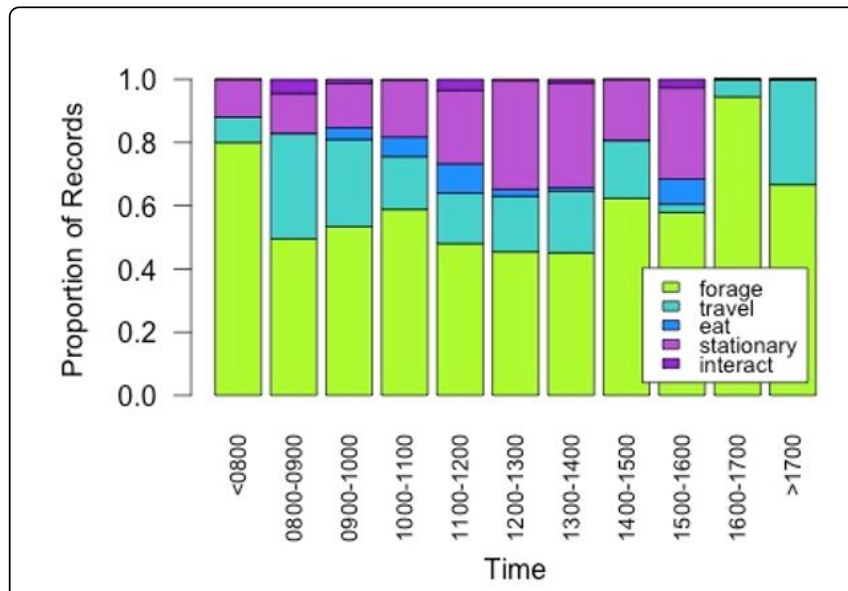

Figure 3: Activity types by time of day.All records of focal animal activity $(n=1,613)$, separated by behavioral class and time bracket.

Female animals spent significantly less time foraging than males (female mean $41 \%$, male $63 \%$; t-test $\mathrm{p}=0.004$ ), and a significantly greater proportion of the time traveling (female mean $32 \%$, male $16 \%$; t-test $\mathrm{p}=0.02)$. Overall behavior was significantly contingent on sex $(\mathrm{X} 2, \mathrm{df}=4, \mathrm{p}$-value $=1.073 \mathrm{e}-06)$. Dogs rarely hunted successfully $(\mathrm{n}=15)$, 
and when they did, they killed small rodents such as Blick's grass rats (Arvicanthis blicki). Dogs freely scavenged from animal material available, both feeding from relatively fresh carcasses and chewing old bones and skin.

Although dogs spent the nights in human settlements, their movements centered not on the villages, which skirt the valley walls, but on the central valley itself (Figure 4a). Indeed, the concentration of eating behavior indicates the main foraging ground is away from villages, in the same core area as used by the wolves. Stationary behavior was broadly the same as general movement, suggesting the dogs were indiscriminate about resting sites.

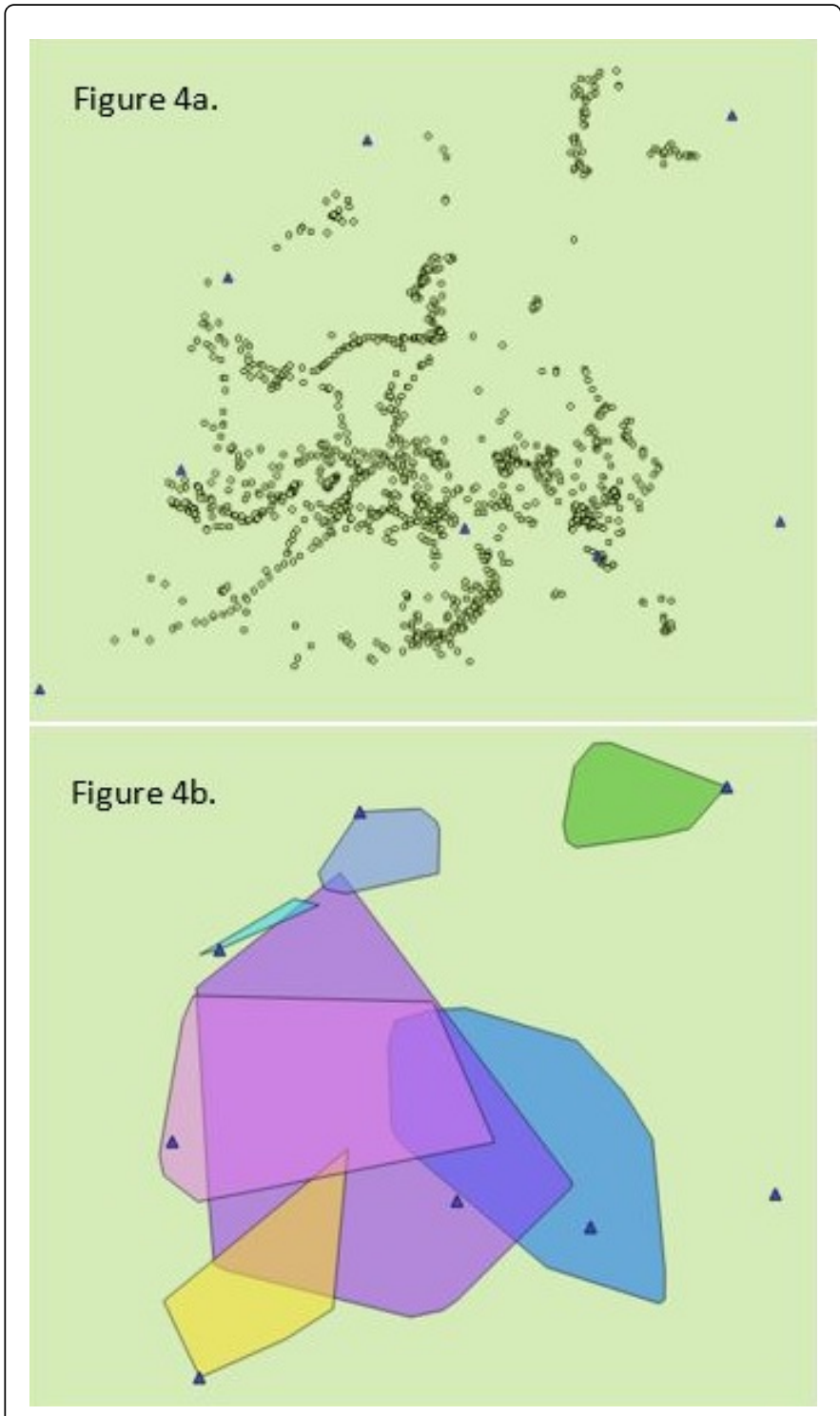

Figure 4: Maps of Dog Movement in BMNP. Blue triangles represent human settlements (4a) Green points represent individual dog records (4b) $100 \%$ convex polygons of all dog movements, separated by village (colors represent different villages).

The dogs ranged widely, moving an average of $1.57 \mathrm{~km}$ per follow ( \pm SE 0.19 ; follow lengths $<10$ minutes excluded). Males moved significantly further per follow (mean $1.73 \mathrm{~km} \pm$ SE 0.23 ) than females (mean $0.91 \mathrm{~km} \pm$ SE 0.25 ; t-test, $\mathrm{p}=0.01955)$. Although duration and distance are interrelated, both results are significant (Bonferroni correction $\mathrm{p}=0.039$ for duration/sex; $\mathrm{p}=0.021$ for distance/sex). Speed also varied significantly between the sexes, with males moving faster than females through wolf range (male mean $1.82 \pm$ SE 0.14, female mean $1.28 \pm$ SE 0.14; t-test, $\mathrm{p}=0.006$ ).

Where the home village of the focal animal could be identified $(n=94), 100 \%$ minimum convex polygons were plotted (Figure $4 b$ ). Dogs from all-but-one village (Tarbo) overlapped in their use of space, especially in the central valley. For females, there were fewer focal animals, and polygons only overlapped between two villages (Sodota and Gata).

\section{Interactions between free-ranging dogs and other range users}

Although households generally kept more than one dog, focal individuals were alone in $89.6 \%$ of records. There was no significant difference in dog behavior when alone compared with groups of dogs (mosaic plot, Pearson residuals nonsignificant). In over $40 \%$ of records the focal animal was associated with people, livestock, or both. Dog activity was highly related to company type at any given time (Figure 5), with proportion of time spent foraging declining with presence of livestock, further with people. These differences were highly significant. Differences in eating and stationary behavior between company types were only marginally significant; travelling behavior was significantly more common when with company than alone (Figure 5).

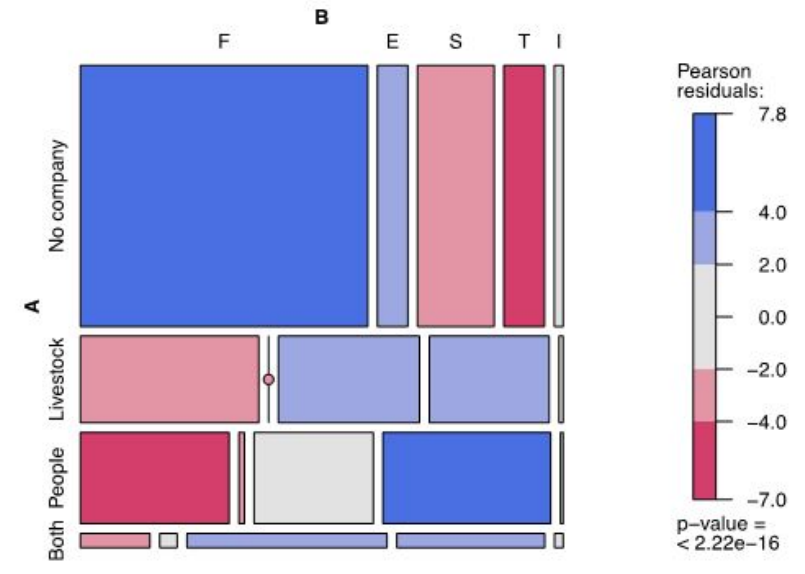

Figure 5: Behavior and Company Type: On B axis: $\mathrm{F}=$ Foraging; $\mathrm{E}=$ Eating; $\mathrm{S}=$ Stationary; $\mathrm{T}=$ Travelling; $\mathrm{I}=$ Interactions. Height of segments on the A axis represents number of records in each category. Width on axis B is proportions of records in each behavioral class. Pearson's residuals show significance of differences in behavior by company type. Darker blue indicates higher proportion than expected; darker pink indicates lower, grey is insignificant.

Dogs moved, on average, further when associated with people and/or livestock than they did alone (mean 1.56 and $1.2 \mathrm{~km}$, respectively), but this difference was not significant ( $\mathrm{t}$-test, $\mathrm{p}=0.28$ ). However, dogs alone moved significantly faster than dogs with 
company of any kind (mean alone $1.89 \mathrm{~km} / \mathrm{h} \pm$ SE 0.17 , mean with company $1.43 \pm$ SE 0.11 ; t-test, $\mathrm{p}=0.025)$.

Wolves and dogs interacted directly on 22 occasions in 162 hours of observation. Wolves avoided dogs in all instances. Direct contact was never observed, but on five occasions dogs actively chased wolves, sometimes initiating the pursuit from substantial distances away $(>300$ $\mathrm{m}$ away, $\mathrm{n}=2)$. In all instances the aggressor was a male dog, and the wolves always retreated irrespective of the number of wolves' present (on separate occasions 2, 3 and 4 wolves were displaced by a single dog). Aggression occurred irrespective of the presence of livestock.

\section{Discussion}

With such high numbers of free-ranging dogs using wolf habitat in BMNP, it is almost inevitable that they will interact with wolves. Indeed, in other protected areas domestic dogs have variously been recorded as predators, disease vectors, and as competitors [5,35-38]. Since interaction between dogs and wolves is increasing as the number of dogs grows, a better understanding of this dynamic is of importance; characterizing both dog behavior and their relationship with wolves were the fundamental aims of this preliminary study, that took place over a brief time period and was therefore limited in scope. Further research should explore these interspecific interactions further, particularly the practical relevance of these interactions in terms of foraging and energetic budget costs.

\section{Dog behavior}

Local reports suggested that most dogs return to their homesteads over the midday period (12:00-14:00 hrs) but this was not substantiated, with most dogs remaining outside their homesteads from 08:00 hrs and only returning in the afternoon. However, over midday there was a reduction in mobile activity (i.e., foraging and travelling), suggesting dogs were more likely to be resting out in wolf range during the hottest part of the day.

Free-ranging dogs utilized most of the available habitat types, spending most of their time in alpine grassland, swamp and Alchemilla habitats. They used the full extent of the Web Valley. Animals foraged wherever they moved, but most interaction and eating behavior was concentrated in the valley floor. There was overlap in the areas used by dogs from different villages, although this was exclusive to male animals - female movement patterns only overlapped between two villages (Sodota and Gata), although this was likely a corollary of fewer females using the wolf range overall.

Generally, animals spent most of their time outside villages engaging in foraging behavior. Despite this, they rarely caught any prey and mainly gleaned small, unidentifiable items from the surface of the substrate. This is in accordance with the previous finding of Atickem, et al. [23] which concluded that dog diet in BMNP was based largely on human-derived materials, namely barley husks and human faeces. However, this previous work did not differentiate the diets of freeranging dogs and those that remained in homesteads; as dogs using wolf range represent only a small proportion of the dog population, this study is the first confirmation that roaming dogs using wolf range are not hunting successfully. Ethiopian wolves are highly specialized rodent predators $[29,39]$ and this finding is of importance in defining the interaction between these two species.

Covering long distances under unforgiving environmental conditions is doubtless energetically costly. For those dogs that engage in such behavior (c. $3 \%$ of the total dog population in the Web Valley [23], it might be expected that there is some substantial benefit to be gained. However, given how little foraging success dogs appear to have, what this benefit is remains obscure. There are many possible explanations for this ranging behavior.

Although dogs appear to gain little extra food through foraging in the Web Valley, that which they do access may be energetically important, supplying vitamins or minerals not available elsewhere. It is beyond the scope of this study to explore the energetic contribution of the miscellaneous food items which dogs scavenge from wolf habitat. Identification of the items being foraged by dogs is key to understanding better the function of ranging behavior.

The primary motive for ranging behavior may not be access to food, but some other resource only available outside villages. Indeed, for male dogs, access to mating opportunities with female wolves may provide an incentive for leaving villages. Although not observed during this study, hybridization and mating behavior between male dogs and female wolves have both been previously documented [40]. Indeed, hybridization is of concern for wolf genetic integrity. This research found that male dogs travelled further, faster, and remained in wolf range for longer than female dogs, perhaps suggesting that males benefit more from using wolf range than do female dogs, providing some speculative support for this hypothesis.

Since only a very small proportion of the dog population foraged outside villages, competition for resources was less fierce away from human habitation. By roaming, dogs may benefit by avoiding both exploitative competition from food, and interference competition from other dogs in their village. Despite park regulations permitting only two dogs per household, the average number of dogs on each homestead is much higher [24] with villages consequently hosting tens of dogs. Village dogs were regularly observed fighting, with animals often bearing sores or wounds as a result; in moving outside villages dogs might be better able to avoid intraspecific competition. If avoidance of competition was the motivation for ranging behavior, it might be expected that those individuals most negatively affected by any such competition - i.e. the weak or infirm - would be most likely to move outside villages. This study does not support such a suggestion, if anything finding the converse: most free-ranging dogs were healthy adult males. Further work comparing the physiological properties of ranging and more static dogs would help substantiate or disprove this competition-based hypothesis.

\section{Interspecific interactions}

Dogs are kept for their nocturnal livestock guarding capacity: livestock are brought back to the vicinity of villages overnight, with small stock being herded into protective bomas to reduce the risk of predation. The dogs are effective in alerting their owners to the presence of carnivores [30]. Thus, although all study animals belong to a household, during the day, when livestock are herded out to graze in wolf habitat, dogs are free to range within the BMNP [41]. Despite this freedom, dogs often chose to associate with humans and/or their livestock. This study found major effects of the presence of people and/or livestock on dog behavior, with animals foraging alone spending a greater proportion of their time foraging than did those with livestock or people.

Although proportion of time spent with other users of wolf range and behavior performed were related, it is unclear whether this was due to differences in individual dogs- i.e. that the dogs which spent 
Page 6 of 7

more time with livestock and people were also less likely to forage, or whether the presence of cattle and people was enough to subvert the desire to forage on an individual level. Follow up studies should concentrate on understanding the effect of company type on the behavior of individual focal animals.

In this study, there were no records of direct physical contact between dogs and wolves, but there were numerous recorded pursuits of wolves by dogs. Although it was not observed, the nature of these pursuits implies that physical conflict must surely occur, albeit at low frequency. Despite similar body sizes, dogs dominated wolves in all interactions, and wolves were displaced from habitat. This result should be treated with caution: others have documented wolves displacing dogs [30]. Irrespective, since dogs were utilizing almost the entire extent of the Web Valley, displacing wolves at least a proportion of the time, dog presence has the potential to impact wolves substantially.

Although sample sizes were small, this study recorded an effect of sex on behavior. Male dogs travelled further, faster, and for longer than female dogs. Within these periods of park use, they spent a significantly greater proportion of the time foraging than female animals. Moreover, they also travelled further from their home villages, and males from differing villages overlapped more in the area they utilized, potentially making their role in disease transmission more significant than that of females. Further, all records of wolf-directed aggression, from barking to active pursuit, were by male dogs; females were never observed to behave aggressively towards wolves. Arguably the factors that most increase the direct conflict between wolves and dogs are the extent (i.e. the duration and distance travelled) of habitat use, the type of behavior carried out in wolf habitat, and the propensity of individuals to be actively aggressive towards wolves. In these respects, male dogs present more of a problem to wolves than do female dogs. Consequently, male dogs may have a more important role in transmission of disease within the dog population, and therefore are more important in maintaining the reservoir of disease, due to greater suggested connectivity between the males of different villages [42-45]. Further, since they range more widely from villages, and may even be more likely to come into physical contact with wolves through direct aggression, males could also be more important than female dogs in spill-over transmission of infectious diseases to wolves [43].

More broadly, this preliminary result raises an interesting question, applicable to all regions where domestic dogs interact with wildlife: are there sex-based differences- in habitat use, behavior, or the interactions of other species with domestic dogs? If so, how do these differences affect species, communities and ecosystems? With domestic dogs having ever more impact on wildlife around the world [35] understanding those factors that determine the nature of interactions between dogs and wildlife has never been of greater importance.

\section{Acknowledgements}

The authors would like to thank the Ethiopian Wildlife Conservation Authority and Bale Mountains National Park for permissions and support. They gratefully acknowledge the support provided by the Ethiopian Wolf Conservation Programme, without which this work would not have been possible. L.R. Perry would like to thank the EWCP and BMNP staff, Eric Bedin and Neville Slade for help with fieldwork, and Brasenose College, Oxford, which partially funded this work.

\section{References}

1. Campos CB, Esteves CF, Ferraz KMPMB, Crawshaw PG, Verdade LM (2007) Diet of free-ranging cats and dogs in a suburban and rural environment, south-eastern Brazil. Journal of Zoology, 273: 14-20.

2. Hughes J, Macdonald DW (2013) A review of the interactions between free-roaming domestic dogs and wildlife. Biological Conservation 157: 341-351.

3. Dos Santos CLA, Silva AP, Dos Santos SB, Pardini R, Cassano CR (2017) Dog invasion in agroforests: The importance of households, roads and dog population size in the surroundings. Perspectives in Ecology and Conservation 15: 221-226.

4. Torres RT, Ferreira E, Rocha RG, Fonseca C (2017) Hybridization between wolf and domestic dog: First evidence from an endangered population in central Portugal. Mammalian Biology-Zeitschrift für Säugetierkunde 86: 70-74.

5. Vanak AT, Gompper ME (2009) Dogs Canis familiaris as carnivores: their role and function in intraguild competition. Mammal Review 39: 265-283.

6. Acosta-Jamett G, Cleaveland S, Cunningham AA (2010) Demography of domestic dogs in rural and urban areas of the Coquimbo region of Chile and implications for disease transmission. Preventive Veterinary Medicine 94: 272-281.

7. Manor R, Saltz D (2004) The impact of free-roaming dogs on gazelle kid/ female ratio in a fragmented area. Biological Conservation 119: 231-236.

8. Yanes M, Suarez F (1996) Incidental nest predation and lark conservation in an Iberian semiarid shrubsteppe. Conservation Biology 10: 881-887.

9. Goheen JR, White EP, Ernest SK, Brown JH (2005) Intra-guild compensation regulates species richness in desert rodents. Ecology 86: 567-573.

10. Fedriani JM, Fuller TK, Sauvajot RM, York EC (2000) Competition and intraguild predation among three sympatric carnivores. Oecologia 125: 258-270.

11. Merkle JA, Stahler DR, Smith DW (2009) Interference competition between gray wolves and coyotes in Yellowstone National Park. Canadian Journal of Zoology 87: 56-63.

12. Tannerfeldt M, Elmhagen B, Angerbjörn A (2002) Exclusion by interference competition? The relationship between red and arctic foxes. Oecologia 132: 213-220.

13. Cypher BL, Spencer KA (1998) Competitive interactions between coyotes and San Joaquin kit foxes. Journal of Mammalogy 79: 204-214.

14. Vanak AT, Gompper ME (2010) Multi-scale resource selection and spatial ecology of the Indian fox in a human-dominated dry grassland ecosystem. Journal of Zoology 281: 140-148.

15. Vanak AT (2008) Intraguild interactions between native and domestic carnivores in central India (Doctoral dissertation, University of Missouri--Columbia).

16. Hayward MW, Kerley GI (2008) Prey preferences and dietary overlap amongst Africa's large predators. South African Journal of Wildlife Research 38: 93-108.

17. Marino J, Sillero-Zubiri C (2013) Canis simensis. IUCN Red List of Threatened Species.

18. Laurenson K, Sillero-Zubiri C, Thompson H, Shiferaw F, Thirgood S, et al. (1998) Disease as a threat to endangered species: Ethiopian wolves, domestic dogs and canine pathogens. In Animal Conservation forum, Cambridge University Press 1: 273-280.

19. Marino J (2003) Threatened Ethiopian wolves persist in small isolated Afroalpine enclaves. Oryx 37: 62-71.

20. Gordon CH, Banyard AC, Hussein A, Laurenson MK, Malcolm JR, et al. (2015) Canine distemper in endangered Ethiopian wolves. Emerging infectious diseases 21: 824.

21. Randall DA, Marino J, Haydon DT, Sillero-Zubiri C, Knobel DL, et al (2006) An integrated disease management strategy for the control of rabies in Ethiopian wolves. Biological Conservation 131: 151-162. 
Citation: Perry LR, Marino J, Sillero-Zubiri C (2018) Going to the Dogs: Free-Ranging Domestic Dogs Threaten an Endangered Wild Canid through Competitive Interactions. J Biodivers Endanger Species 6: 211. doi:10.4172/2332-2543.1000211

Page 7 of 7

22. Sillero-Zubiri CS, Gottelli D (1995) Spatial organization in the Ethiopian wolf Canis simensis: large packs and small stable home ranges. Journal of Zoology 237: 65-81.

23. Atickem A, Williams S, Bekele A, Thirgood S (2009) Livestock predation in the Bale Mountains, Ethiopia. African Journal of Ecology 48: 1076-1082.

24. Jessica CH (2007) Bale Mountains National Park General Management Plan. Ethiopian Wildlife Conservation Organisation, Ministry of Agriculture.

25. Marino J (2003) Spatial ecology of the Ethiopian wolf, Canis simensis (Doctoral dissertation, University of Oxford).

26. Vial F, Sillero-Zubiri C, Marino J, Haydon DT, Macdonald DW (2011) An analysis of long-term trends in the abundance of domestic livestock and free-roaming dogs in the Bale Mountains National Park, Ethiopia. African Journal of Ecology 49: 91-102.

27. Marino J, Sillero-Zubiri C, Macdonald DW (2006) Trends, dynamics and resilience of an Ethiopian wolf population. Animal Conservation 9: 49-58.

28. Hillman JC (1988) The Bale Mountains National Park area, southeast Ethiopia, and its management. Mountain Research and Development 253-258.

29. Sillero-Zubiri C, Gottelli D (1995) Diet and feeding behavior of Ethiopian wolves (Canissimensis). Journal of Mammalogy 76: 531-541.

30. Atickem A, Bekele A, Williams SD (2010) Competition between domestic dogs and Ethiopian wolf (Canis simensis) in the Bale Mountains National Park, Ethiopia. African Journal of Ecology, 48: 401-407.

31. Butler JRA, Du Toit JT, Bingham J (2004) Free-ranging domestic dogs (Canis familiaris) as predators and prey in rural Zimbabwe: threats of competition and disease to large wild carnivores. Biological Conservation 115: 369-378.

32. Vanak AT, Thaker M, Gompper ME (2009) Experimental examination of behavioural interactions between free-ranging wild and domestic canids. Behavioral Ecology and Sociobiology 64: 279-287.

33. Altmann J (1974) Observational study of behavior: sampling methods Behaviour 49: 227-266.
34. Newey S, Sillero-Zubiri C (2000) Monitoring Ethiopian wolf populations. Wildlife Conservation Research Unit, Oxford University.

35. Young JK, Olson KA, Reading RP, Amgalanbaatar S, Berger J (2011) Is wildlife going to the dogs? Impacts of feral and free-roaming dogs on wildlife populations. BioScience 61: 125-132.

36. Barrett T, Blixenkrone-Møller M, Di Guardo G, Domingo M, Duignan P, et al. (1995) Morbilliviruses in aquatic mammals: report on round table discussion. Veterinary microbiology, 44: 261-265.

37. Lenth BE, Knight RL, Brennan ME (2008) The effects of dogs on wildlife communities. Natural Areas Journal 28: 218-227.

38. Lacerda ACR, Tomas WM, Marinho-Filho J (2009) Domestic dogs as an edge effect in the Brasília National Park, Brazil: interactions with native mammals. Animal Conservation 12: 477-487.

39. Marino J, Sillero-Zubiri C, Gottelli D, Johnson PJ, Macdonald DW (2013) The fall and rise of Ethiopian wolves: lessons for conservation of longlived, social predators. Animal Conservation 16: 621-632.

40. Gottelli D, Sillero-Zubiri C, Applebaum GD, Roy MS, Girman DJ, et al. (1994) Molecular genetics of the most endangered canid: the Ethiopian wolf Canis simensis. Molecular Ecology 3: 301-312.

41. Atickem A, Williams S, Bekele A, Thirgood S (2009) Livestock predation in the Bale Mountains, Ethiopia. African Journal of Ecology 48: 1076-1082.

42. Paull SH, Song S, McClure KM, Sackett LC, Kilpatrick AM, et al. (2011) From superspreaders to disease hotspots: linking transmission across hosts and space. Frontiers in Ecology and the Environment 10: 75-82.

43. Daszak P, Cunningham AA, Hyatt AD (2000) Emerging infectious diseases of wildlife--threats to biodiversity and human health. Science 287: 443-449.

44. QGIS Development Team (2016) QGIS Geographic Information System, Open Source Geospatial Foundation Project.

45. RStudio Team (2014) RStudio: Integrated Development for R. RStudio, Inc., Boston, MA. 